
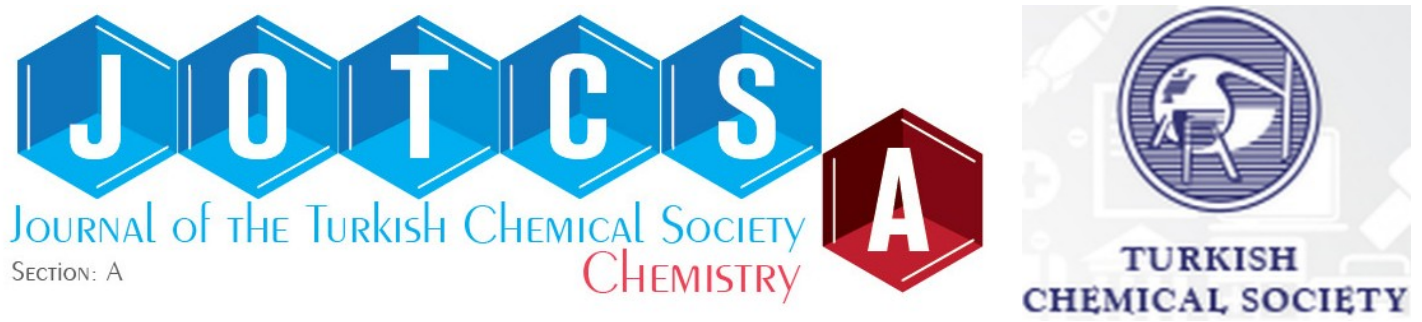

\title{
Preparation, Characterization and Adsorption into Aqueous Solutions of Polyethyleneimine-Coated Silica Nanoparticles
}

\begin{abstract}
Aslı Beyler-Çiğil'
1 Amasya University Technical Sciences Vocational, Department of Chemistry and Chemical Process Technology School, Amasya, Turkey.

Abstract: In this study, polyethyleneimine-coated silica nanoparticles (PEI-SiNP) were used to prepare a polymeric material that can effectively and selectively adsorb Au(III) from aqueous solutions. For this purpose, silica nanoparticles were firstly reacted with (3-glycidyloxypropyl)trimethoxysilane (GPTMS) to achieve epoxy functionality. The structures of the silica nanoparticles (SiNP), silica nanoparticles with epoxy functionality (E-SiNP) and polyethyleneimine-coated silica nanoparticles were determined using ATR-FTIR (Attenuated Total Reflectance Fourier Transform Infrared) and XPS (X-Ray Photoelectron Spectroscopy), while their thermal properties were characterized using thermogravimetric analyses (TGA). The Au(III) ion-binding capacity of the PEI-SiNP adsorbent nanocomposite that contain high levels of imine was investigated. The effects of the interactions between $\mathrm{pH}$, contact time, and foreign metal ions on adsorption were tested to determine the optimum conditions. The optimum contact time was 3 hours at $\mathrm{pH}$ 2. The adsorption capacity of the adsorbent nanocomposite prepared for Au(III) was found to be $116.27 \mathrm{mg} / \mathrm{g}$. The Langmuir and Freundlich isotherms were used to determine the adsorption behaviors and the Langmuir isotherm model was selected as the best fit model $\left(R^{2}: 0.997\right)$. The prepared PEI-SiNP adsorbent nanocomposite showed a high selectivity for the Au(III) ion even when different metal cations such as $\mathrm{Cu}(\mathrm{II}), \mathrm{Cd}(\mathrm{II})$, and $\mathrm{Pb}(\mathrm{II})$ were present.
\end{abstract}

Keywords: Au(III), Epoxy Functionality, Polyethyleneimine, Silica Nanoparticles, Surface Modification

Submitted: September 01, 2020. Accepted: October 20, 2020.

Cite this: Beyler-Çiğil A. Preparation, Characterization and Adsorption into Aqueous Solutions of Polyethyleneimine-Coated Silica Nanoparticles. JOTCSA. 2020;7(3):883-92.

DOI: https://doi.org/10.18596/jotcsa.788852.

*Corresponding author. Asli.beyler@amasya.edu.tr Tel: 05542345428.

\section{INTRODUCTION}

Gold is a valuable metal that is mostly found together with other metals such as silver, iron, and copper in nature (1). In addition to its appeal and shine, gold is well-known for its exceptional conductivity, ductility, malleability, and chemical stability $(2,3)$. Thanks to its special physical and chemical properties, this valuable metal is widely used in jewelry production, production of electrical and electronic devices, aviation, and medical applications (4). Moreover, it exponentially gains value in human life due to the countless technological achievements and developments. Although gold is demanded in industrial activities, its amount in Earth's crust is limited and its extraction from ore has various environmental impacts. Therefore, the investigation of cheap and productive separation methods for the recovery of gold is advantageous both in terms of environment and economy (5). Different methods including liquid-liquid extraction (6), ion exchange (7), solid phase extraction (8), cloud point extraction (9), sedimentation (10), electrodeposition, and adsorption (11) were used both for determining its amount in different environments and its recovery.

Compared with other separation methods, adsorption have attracted attention in recent years because of the ease of use, high efficiency, and low 
cost of solid adsorbents and their suitability for use in the adsorption of $\mathrm{Au}$ (III) ions $(12,13)$. In addition to their use in the recovery of valuable elements from aqueous solutions, adsorption is highly effective in the removal of toxic metal ions (14-16).

Various organic and inorganic adsorbents have been produced to remove $\mathrm{Au}(\mathrm{III})$ ions from aqueous solutions (17-19). In most studies, synthetic or biobased polymeric resins or inorganic particles (silica, magnetite, etc.) were functionalized using ligands such as ethylenediamine, 2-mercaptobenzothiazole, guanyl thiourea, dithiooxamide, imidazole, 2(diethylamino) or typically using organic molecules that have nitrogen and sulfur groups.

There have been extensive investigations for hybrid and composite materials because of their different properties (20-22). Their properties couple the advantages of inorganic materials (i.e. rigidity, thermal stability) with those of organic materials (i.e. flexibility, ductility, and processability). Therefore, organically modified silica nanoparticles are typically classified as hybrid materials (23). Modified silica nanoparticles have been extensively investigated in recent years because of their unique properties (24). Silica molecules have high-density hydroxyl groups and can be modified with specific functional groups such as carboxyl, amino, and chloro for various applications. Some studies have investigated the use of organically modified silicas in wastewater (25-27).

The study aims to prepare PEI-coated silica nanoparticles that can selectively and effectively adsorb Au(III) ions. For this purpose, the hard/soft acid/base (HSAB) theory of Pearson, who asserted that soft acids such as Au(III) ions had a strong interaction with soft bases such as nitrogen and sulfur-containing groups, was taken into consideration and polyethyleneimine that contains high levels of imine was selected as the polymeric surface.

\section{EXPERIMENTAL SECTION}

\section{Materials}

(3-Glycidyloxypropyl)trimethoxysilane

(GPTMS), polyethyleneimine (PEI) (Mw $\sim 10000 \mathrm{~g} / \mathrm{mol}$ ) and all solvents used were from Sigma Aldrich. Nanosilica (12 nm, AEROSIL ${ }^{\circledR} 200,200 \mathrm{~m}^{2} / \mathrm{g}$ surface area) obtained from Evonik.

\section{Preparation of the silica nanoparticles with} epoxy end-groups (E-SiNP)

The procedure for the functionalization of the silicas with epoxy groups was adapted in a similar fashion to that of the procedures in the literature (28-30). Prior to use, AEROSIL ${ }^{\circledR} 200$ nanoparticles were firstly dried in a vacuum drying oven at $150{ }^{\circ} \mathrm{C}$ for 24 hours. Five-grams of silica nanoparticles were dispersed into $300 \mathrm{~mL}$ of toluene and 10 -grams of
GPMTS were added. The mixture was kept in an ultrasonic bath for 30 minutes and, then kept in a condenser for 24 hours. Silica nanoparticles with epoxy end-groups were separated using centrifugation and purified for 48 hours using Soxhlet extraction with toluene. The particles were lastly dried in a vacuum drying oven at $100^{\circ} \mathrm{C}$.

\section{Preparation of the adsorbent material (PEI- SiNP)}

Five grams of the silica nanoparticles with epoxy end-groups were collected in a reaction flask and, then $15 \mathrm{~mL}$ of water and $6 \mathrm{~g}$ of PEI were added to the flask. The mixture was then kept in a shaking water bath at $65^{\circ} \mathrm{C}$ for 24 hours. The prepared adsorbents were then rinsed with a $\mathrm{NaCl}$ solution and phosphate buffer at $\mathrm{pH} 5$ and kept in a vacuum drying oven at $60{ }^{\circ} \mathrm{C}$ for 24 hours. Figure 1 shows all modifications made to the silica nanoparticles to obtain the adsorbent.

\section{Characterization}

The structure analyses of the silica nanoparticles with epoxy end-groups (E-SiNP) and PEI-coated silica nanoparticles (PEI-SiNP, adsorbent) were carried out using ATR-FTIR and XPS. The XPS analyses were performed using the Thermo Scientific K-Alpha X-ray Photoelectron Spectrophotometer in the Boğaziçi University Advanced Technologies Research and Development Center. The ATR-FTIR spectra were recorded using the Perkin Elmer Spectrum 100 ATR-FTIR spectrometer.

The thermogravimetric analyses of the silica nanoparticles, silica nanoparticles with epoxy endgroups, and PEI-coated silica nanoparticles were carried out using a model Pyris 1 TGA Perkin-Elmer Thermogravimetric analyzer. The measurements were made under nitrogen atmosphere and at temperatures between 30 and $750{ }^{\circ} \mathrm{C}$ at a heating rate of $20^{\circ} \mathrm{C} /$ minute.

An Analytic Jena Zeenit 700 flame atomic absorption spectrophotometer equipped with a deuterium lamp (Jena, Germany) was used to determine the amount of $\mathrm{Au}(\mathrm{III})$ ions.

\section{Adsorption of $\mathrm{Au}$ (III) ions}

The adsorption trials were carried out using $0.005 \mathrm{~g}$ PEI-coated silica nanoparticles and $50-\mathrm{mL}$ glass jars that contained $15 \mathrm{~mL}$ Au(III) solutions at different concentrations. The jars were stirred at $250 \mathrm{rpm}$ and room temperature. The effect of $\mathrm{pH}$ on the adsorption capacity of polymer-coated silica nanoparticles was examined at a constant Au(III) concentration of $10 \mathrm{mg} / \mathrm{L}$ and in the range of $\mathrm{pH} 1$ 5. The initial $\mathrm{pH}$ values were adjusted using $\mathrm{HCl}$ and $\mathrm{NaOH}$ and no significant $\mathrm{pH}$ change was observed throughout the contact time. To determine the intensity of the contact time, the adsorbents were immersed in a $50 \mathrm{mg} / \mathrm{L} \mathrm{Au(III)}$ solution at $\mathrm{pH} 2$ for 
an interval of 30-400 minutes. The adsorption isotherms were obtained with a 3-hour contact time at $\mathrm{pH} 2$ using the initial $\mathrm{Au}$ (III) solutions at different concentrations $(5-500 \mathrm{mg} / \mathrm{L})$. When the equilibrium was established, the aqueous solutions were separated from the adsorbent and final Au(III) ion concentrations were analyzed using flame atomic absorption spectrophotometry. All adsorption trials were repeated in triplicate and the mean values were recorded. The Au(III) ion concentrations per a unit mass of absorbent were calculated using the below equation:

$$
\mathrm{q}_{\mathrm{e}}=\left(\frac{C_{0}-C_{e}}{m}\right) \times \mathrm{V}
$$

Here, $\mathrm{C}_{0}$ and $\mathrm{C}_{\mathrm{e}}$ represent the concentrations $(\mathrm{mg} / \mathrm{L})$ of $\mathrm{Au}(\mathrm{III})$ ions in the aqueous phase before and after adsorption time, respectively; $\mathrm{V}$ represents the volume of the aqueous phase $(L) ; q_{e}$ represents the equilibrium adsorption capacity $(\mathrm{mg} / \mathrm{g})$ and $\mathrm{m}$ represents dry adsorbent amount (g) (31).

\section{RESULTS AND DISCUSSION}

\section{XPS}

XPS analysis was used to determine the element compositions of the silica nanoparticles with epoxy end-groups and PEI-coated silica nanoparticles. The surface analysis was carried out by examining the XPS spectra to evaluate the modification of imine and epoxy groups to silica nanoparticles. Figure 2 shows the XPS spectra of the silica nanoparticles and epoxy- and PEI-modified silica nanoparticles. Strong $O$ 1s (533.2 eV) and Si 2p (103.5 eV) peaks are characteristic of silica nanoparticles. A Si and a few $O$ peaks between the 25 and $104 \mathrm{eV}$ energy interval are considered as the fingerprints of silica nanoparticles (32). Moreover, C 1s (283.8 eV) was observed due to hydrocarbon contamination residues that interacted during sample preparation for XPS. Carbon is found everywhere and, thus, it is detected in all samples exposed to the atmosphere (Figure 2a) (33-35). Table 1 shows the XPS element compositions of the non-modified silica nanoparticles and silica nanoparticles with a modified surface. Figure $2 b$ shows the sweeping result after the reaction of silica nanoparticle and GPTMS. Here, when the spectrum of the nonmodified silica nanoparticles was compared (Figure $2 a$ ), the increases in $\mathrm{C}$ and $\mathrm{O}$ indicated the presence of glycidoxypropyl and epoxy. In compliance with the ATR-FTIR spectrum below, it shows that the GPTMS was successfully grafted onto the silica nanoparticle. The peaks and element compositions found in the study agree with the literature (36). In addition, the $\mathrm{C} 1 \mathrm{~s}$ and $\mathrm{O}$ 1s peaks in the PEI-silica nanoparticles were observed at near $284 \mathrm{eV}$ and $532 \mathrm{eV}$, respectively. The $\mathrm{C}$ 1s peak at $285 \mathrm{eV}$ generally corresponds to $\mathrm{C}-\mathrm{C}$ and $\mathrm{C}-\mathrm{N}$ bonds and, more importantly, as seen in Table 1 , it contained $30.31 \%$ nitrogen after treatment with PEI in addition to all observed elements (37). This proves that there were nitrogen atoms on the surface that originated from PEI.

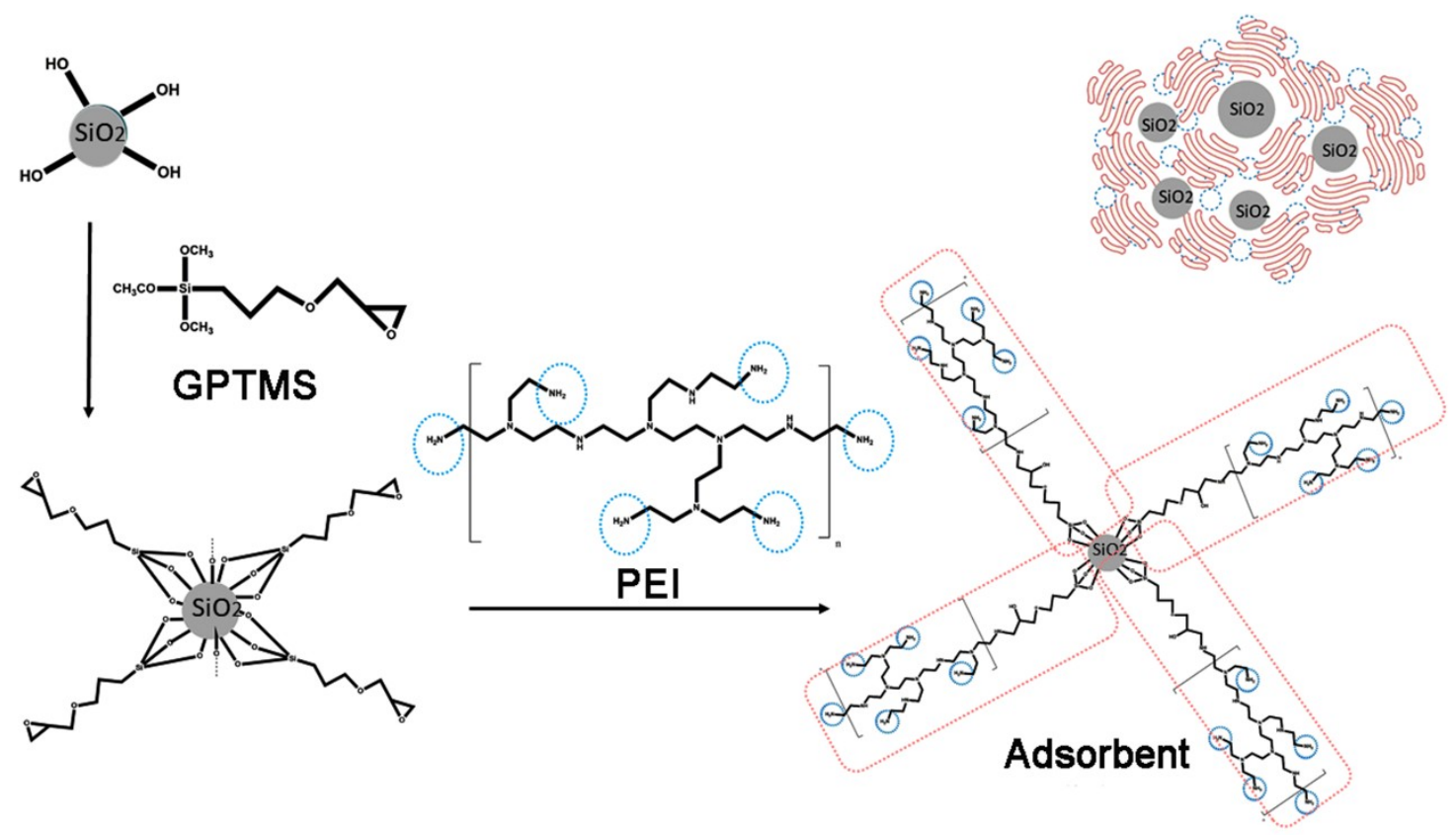

Figure 1: Preparation of the PEI-SiNP adsorbent. 
Table 1: Elemental compositions of silica nanoparticles before and after surface modifications.

$$
\begin{array}{llll}
\mathbf{C} & \mathbf{O} & \mathbf{S i} & \mathbf{N}
\end{array}
$$

\begin{tabular}{ccccc}
\hline SiNP & 8.06 & 55.41 & 36.53 & - \\
E-SiNP & 13.48 & 55.52 & 31.00 & - \\
& & & & \\
PEI-SiNP & 24.15 & 36.56 & 28.99 & 30.31 \\
\hline
\end{tabular}
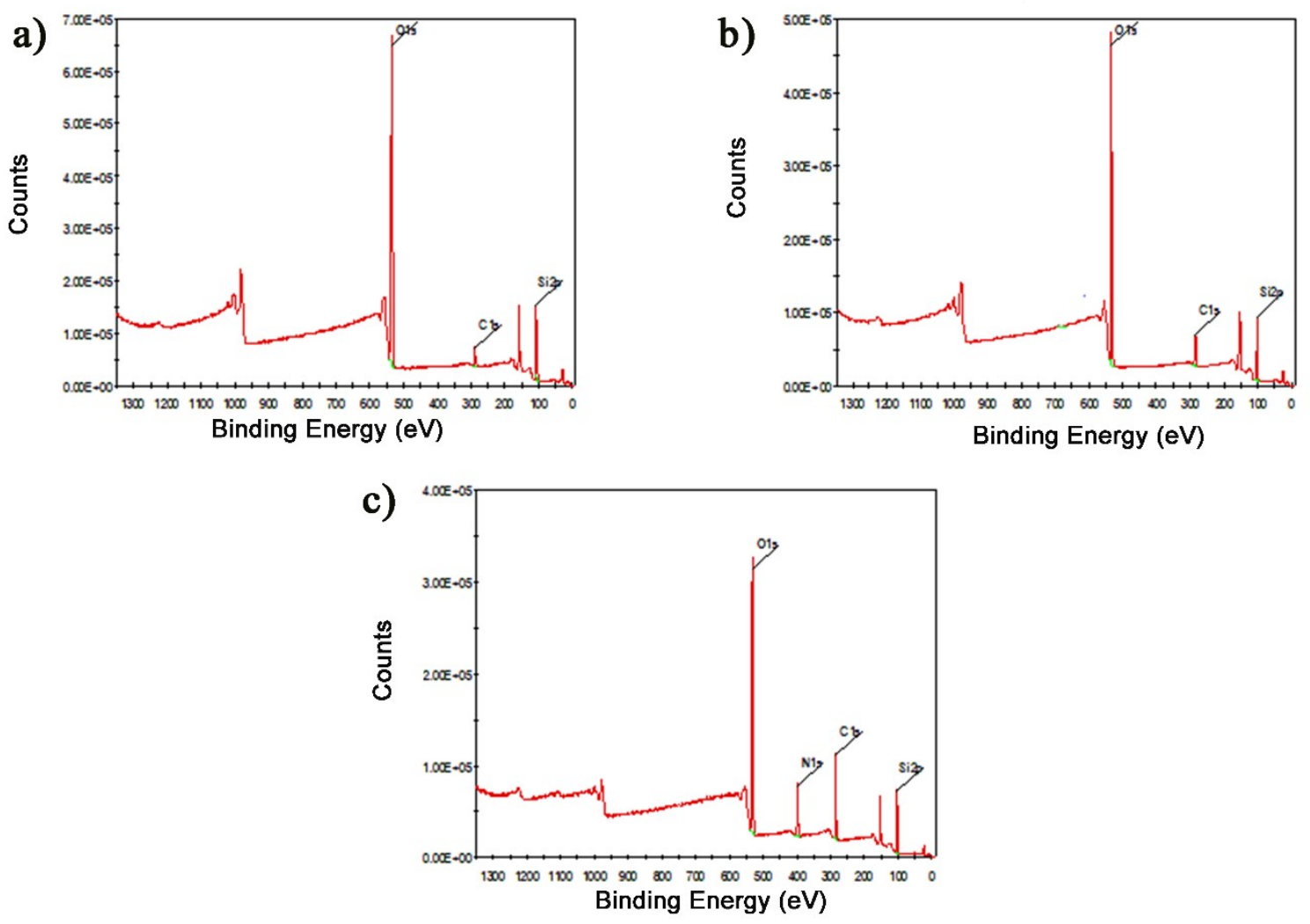

Figure 2: XPS spectra of a) Silica nanoparticles, b) epoxy modified silica nanoparticles and c) PEI coated silica nanoparticles.

\section{ATR-FTIR}

ATR-FTIR analysis was used to determine the functional groups of the silica nanoparticles, silica nanoparticles with epoxy end-groups, and PEIcoated silica nanoparticles. As seen in Figure 3, the peaks at $1087 \mathrm{~cm}^{-1}, 806 \mathrm{~cm}^{-1}$, and $472 \mathrm{~cm}^{-1}$ are characteristic of $\mathrm{SiO}_{2}$ (38). The weak peak at 1261 $\mathrm{cm}^{-1}$ is attributed to the stretching vibration of the epoxy group, indicating that the epoxy groups were successfully modified on the surface of the $\mathrm{SiO}_{2}$ nanoparticle (Figure 3b) $(39,40)$. Figure 3c shows the polyethyleneimine-treated silica nanoparticles. Here, an epoxide ring-opening occurs between polyethyleneimine and epoxy ring. This is confirmed by the decreased density of the characteristic bands of epoxide ring (i.e. $915 \mathrm{~cm}^{-1}$ and $831 \mathrm{~cm}^{-1}$ ) and primary amine (i.e. $3206 / 3316 \mathrm{~cm}^{-1}$ ) and the increased density of the $-\mathrm{OH}$ band (i.e. $3380 \mathrm{~cm}^{-1}$ ) and secondary amine groups (i.e. $1573 \mathrm{~cm}^{-1}$ ) $(41,42)$. In the literature, similar peaks were observed in the triethylenetetramine treatment of epoxy-modified silica nanoparticles. 


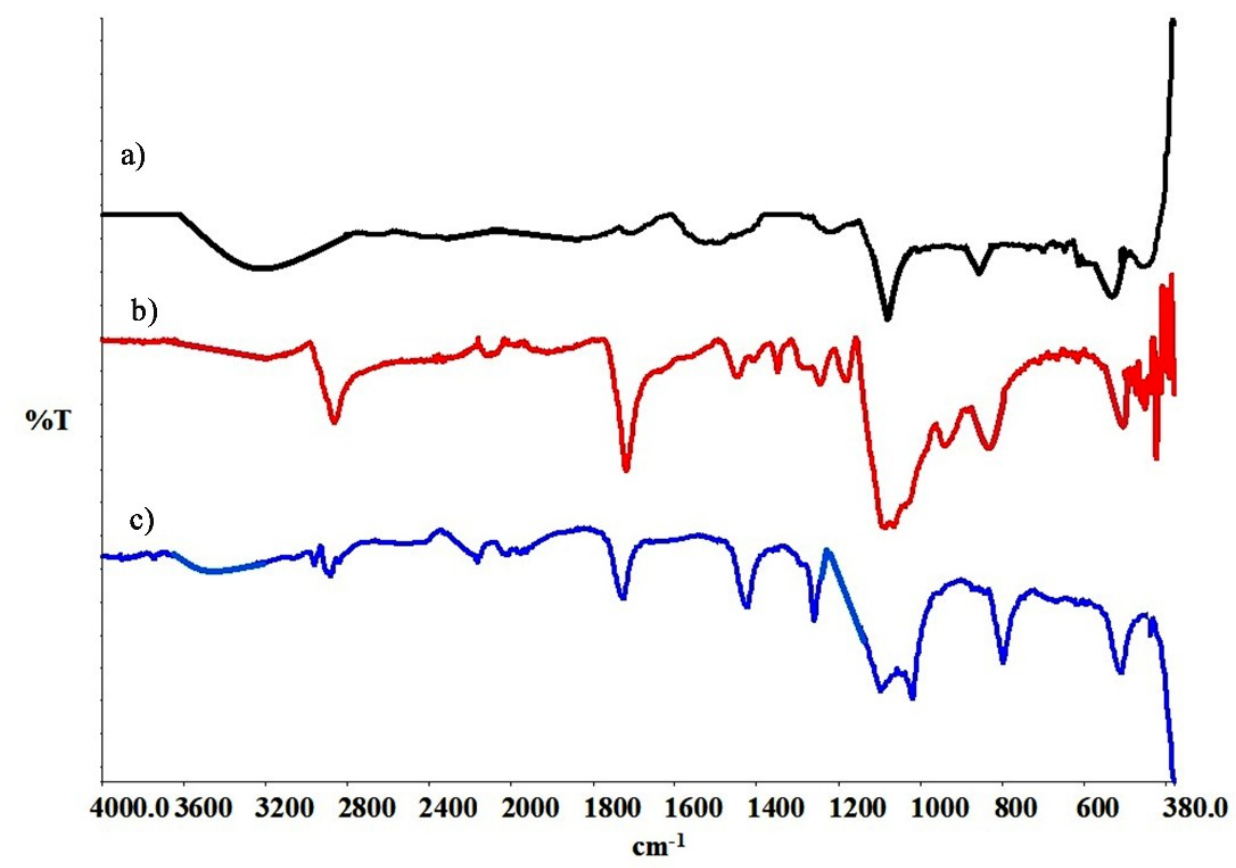

Figure 3: FTIR spectra of a) silica nanoparticles, b) epoxy modified silica nanoparticles, and c) PEI-coated silica nanoparticles.

\section{TGA}

Thermogravimetric analysis (TGA) was carried out to examine the thermal stability of the adsorbent and approximately determine the amount of modification occurring on the surface. Figure 4 shows the thermal degradation behaviors of the silica nanoparticle, epoxy-modified silica nanoparticle and adsorbent nanocomposite under nitrogen atmosphere. As seen in the figure, sample weight decreased by about $1 \%$ as temperature increased from 0 to $120{ }^{\circ} \mathrm{C}$ for the non-modified silica nanoparticles. Weight decreased from $99 \%$ to about $90 \%$ when temperature increased from 120 ${ }^{\circ} \mathrm{C}$ to $750{ }^{\circ} \mathrm{C}$. The weight loss is associated with the loss of the condensation water that formed by the polycondensation of surface hydroxyl groups. Considering the $\mathrm{SiO}_{2}$ nanoparticles that were functionalized with epoxy groups, a weight loss of about $27 \%$ occurs at temperatures between $300{ }^{\circ} \mathrm{C}$ and $750{ }^{\circ} \mathrm{C}$ in response to the thermal degradation of the functional groups on the surface (43). This can be explained by the loss of the epoxy group that was grafted onto the silica nanoparticle. In the case of the prepared adsorbent nanocomposite, actual degradation began at temperatures between $200{ }^{\circ} \mathrm{C}$ and $500{ }^{\circ} \mathrm{C}$ and weight loss reached around $40 \%$. In conclusion, we are of the opinion that the epoxy groups and polyethyleneimine attached to the silica nanoparticle surface at a ratio of $17 \%$ and $30 \%$, respectively.

\section{Effect of pH on metal adsorption}

The changes in the $\mathrm{pH}$ value of solutions affect the surface load of the adsorbent materials and, thus, the $\mathrm{pH}$ value of an aqueous solution is an important factor (44). The $-\mathrm{NH}_{2}$ in the structure of the polymer-coated nanoparticle adsorbent is protonated to the $\mathrm{NH}_{3}{ }^{+}$structure in an acidic environment. Adsorption considerably increases due to the electrostatic attraction between $\mathrm{Au}$ (III) ions, which are in the form of $\mathrm{AuCl}_{4}{ }^{-}$in an acidic environment, and $-\mathrm{NH}_{3}{ }^{+}(45,46)$. The activity of the adsorbent at a $\mathrm{pH}$ range of 1-5 was investigated to find the most suitable $\mathrm{pH}$ value for the $\mathrm{pH}$ study carried out in an acidic environment. As seen in Figure 5, the most suitable $\mathrm{pH}$ for the polymercoated nanoparticle adsorbent was determined to be $\mathrm{pH} 2$.

\section{Effect of contact time}

Metal removal from wastewater sources is a timeconsuming process. The amount of metal ions removed from aqueous solution gradually increases until saturation. Thus, contact time is an important parameter for applicable methods. The adsorbent was examined in the 30-400-minute interval to obtain maximum $\mathrm{Au}$ (III) ion adsorption with the prepared adsorbent. The maximum extraction performance for the adsorbent was obtained with 180 minutes (3 hours) (Figure 6). Insufficient space is left for adsorption after adsorbent reaches saturation. Hence, no increase in adsorption was observed after three hours. 


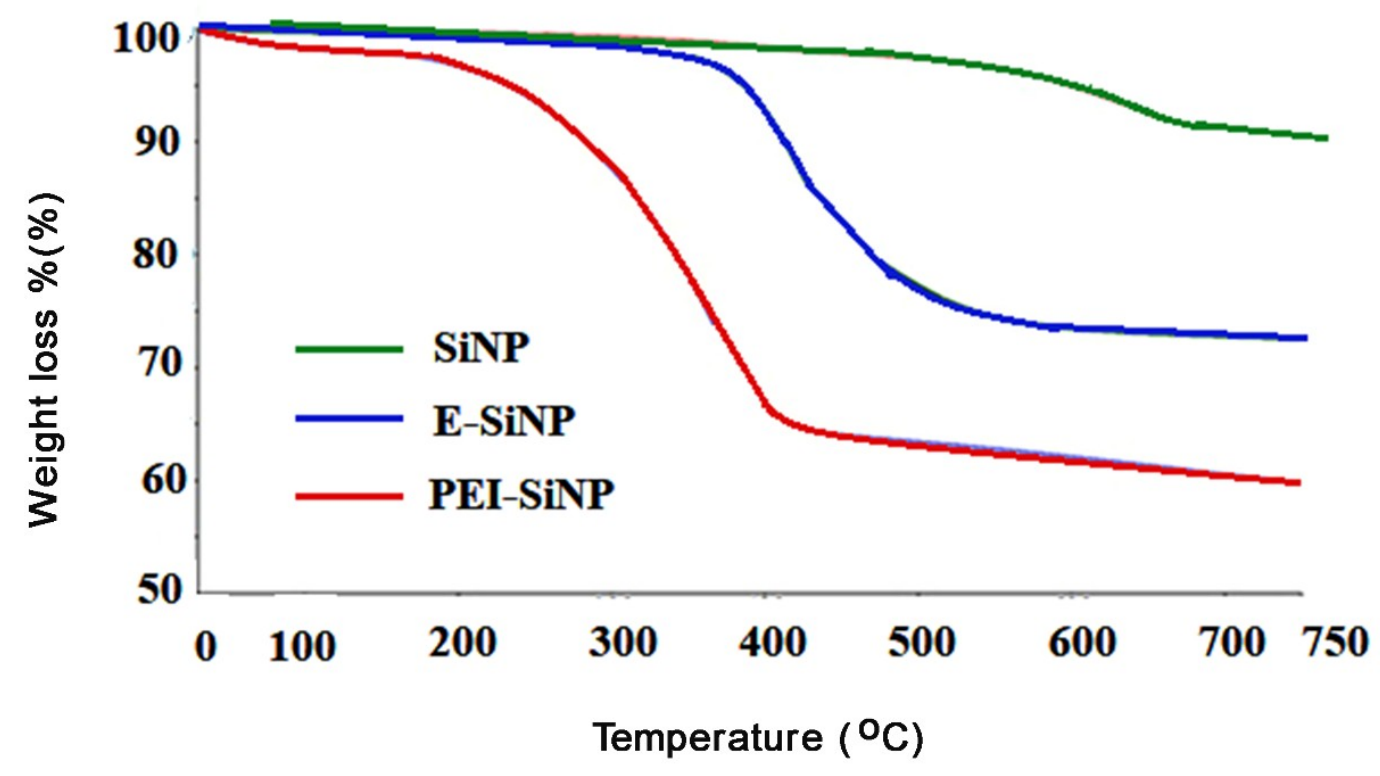

Figure 4: TGA thermograms.

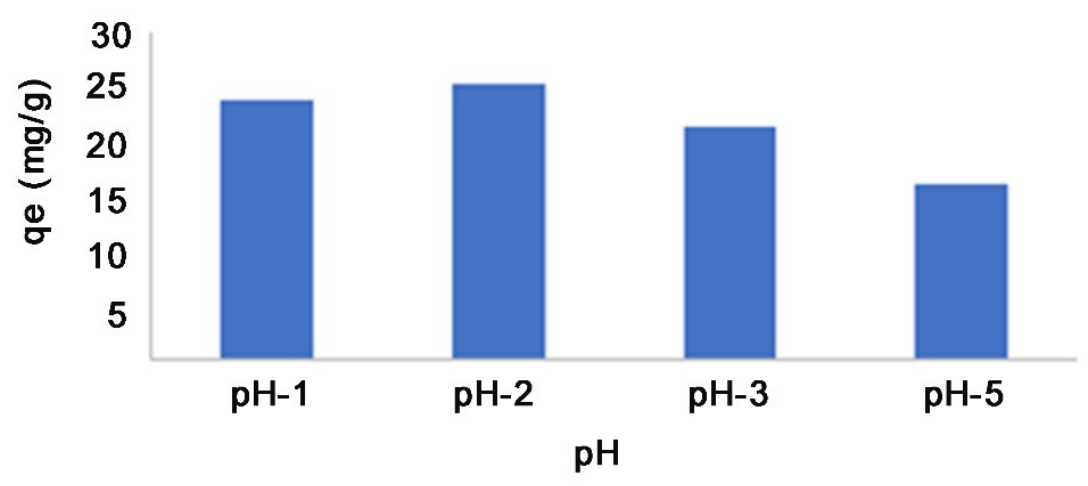

Figure 5: Effect of $\mathrm{pH}$ on the adsorption of $\mathrm{Au}(\mathrm{III})$ ions.

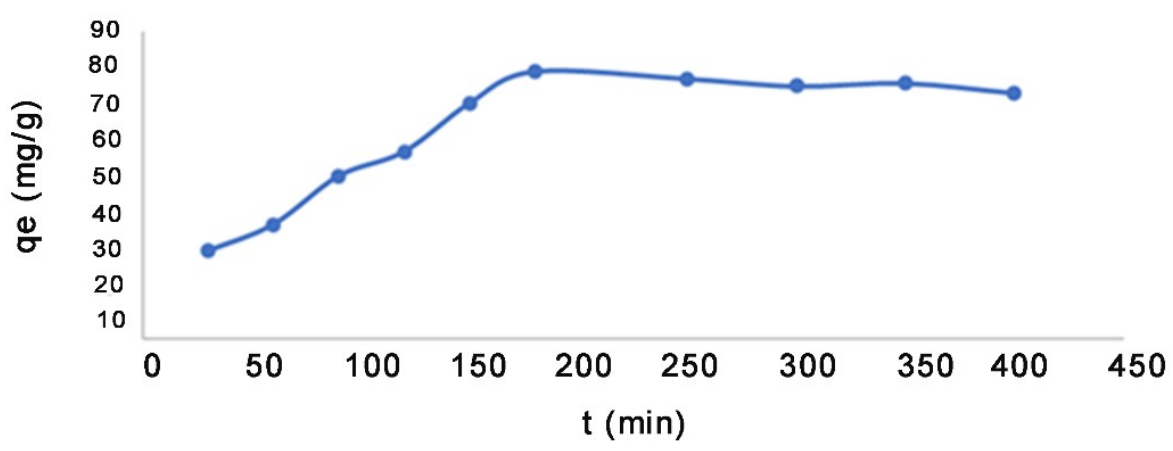

Figure 6: Effect of contact time on $\mathrm{Au}(\mathrm{III})$ ion adsorption. 


\section{Adsorption isotherms}

$\mathrm{Au}(\mathrm{III})$ solutions of different concentrations ranging from $5 \mathrm{mg} / \mathrm{L}$ to $300 \mathrm{mg} / \mathrm{L}$ were used to investigate the affinity of the polymer-coated nanoparticle adsorbent to Au(III) ions. Adsorption capacity curve became relatively flattered at a higher concentration than the initial concentration of $200 \mathrm{mg} / \mathrm{L}$, indicating that the adsorbent reached saturation (Figure 7).

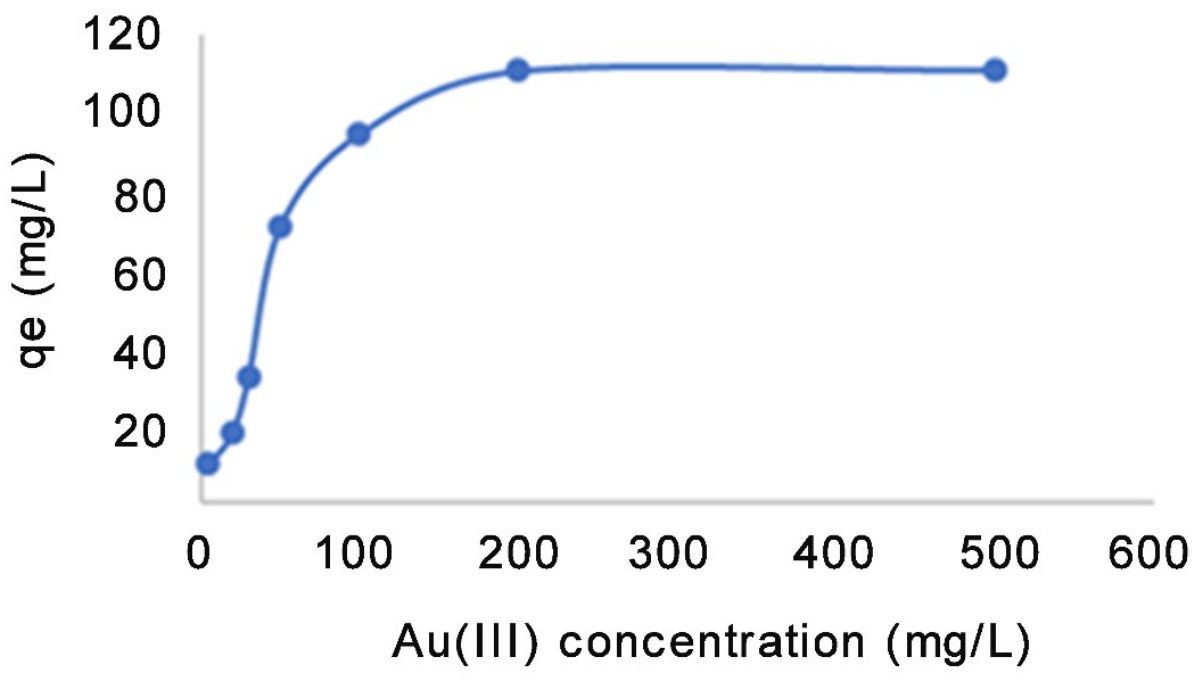

Figure 7: Effect of initial metal concentration on adsorption.

The adsorption performance of the PEI-SiNP prepared in this study was compared with the adsorbents used to some of the related studies in literature. As seen in Table 2, Au(III) was adsorbed in a very high amount compared to other similar work during the 3 hour adsorption period.

Table 2. Comparison of the adsorption performance of the PEI-SiNP with some recent adsorbent for uptake of $\mathrm{Au}$ (III) ions reported in literature

\begin{tabular}{lcccc}
\multicolumn{1}{c}{ Adsorbent } & pH & Contact time & $\mathbf{Q}_{\max }(\mathbf{m g} / \mathbf{g})$ & Reference \\
\hline OSTE-IM & 1.5 & $5 \mathrm{~h}$ & 48.8 & $(46)$ \\
Amberlite XAD 7 & $<4$ & $1 \mathrm{~h}$ & 1 & $(47)$ \\
Amberlite XAD 7-L-glutamic acid & $<4$ & $1 \mathrm{~h}$ & 14.2 & $(47)$ \\
Poly(acrylamide-1-allyl-2-thiourea) hydrogels & 0.5 & $90 \mathrm{~h}$ & 940 & $(48)$ \\
PEI-SiNP & 2 & $3 \mathrm{~h}$ & 116.27 & This study \\
\hline
\end{tabular}

Equilibrium studies are required obtain the adsorption isotherms that are important in the determination of the capacity and especially the surface properties of the adsorbent. Information about the interaction between the polymer-coated nanoparticle absorbent and $\mathrm{Au}(\mathrm{III})$ ions are provided by isotherm studies. The Langmuir and Freundlich isotherms that are given below in respective order are used for this purpose $(46,49)$.

$$
\frac{C_{e}}{q_{e}}=\frac{1}{q_{\max }} C_{e}+\frac{1}{K_{L} q_{\max }}
$$

qmax: Maximum adsorption capacity of the adsorbent $\mathrm{K}_{\mathrm{L}}$ : Langmuir absorption constant

$$
\ln q_{e}=\ln K_{f}+\frac{1}{n} \ln C_{e}
$$

$\mathrm{n}$ : Constant, $\mathrm{K}_{f}=$ Freundlich constant

Table 3 shows a summary of the constants of the adsorption isotherms. The experimental data on the adsorption of $\mathrm{Au}(\mathrm{III})$ ions on the polymer-coated nanoparticle adsorbent had a high correlation coefficient of $R^{2}$ : 0.9952 and was a good fit to the Langmuir model. The Langmuir isotherm indicates that a homogenous and single-layer surface adsorption occurred on the adsorbent surface.

Table 3. Isotherm parameters

\begin{tabular}{cccc}
\hline & $\mathbf{Q}_{\max }(\mathbf{m g} / \mathbf{g})$ & $\mathbf{K}_{\mathbf{L}}(\mathbf{L} / \mathbf{m g})$ & $\mathbf{R}^{\mathbf{2}}$ \\
\hline Langmuir & 116.27 & 0.052 & 0.9952 \\
& $\mathbf{n}$ & $\mathbf{K}_{\boldsymbol{f}}$ & $\mathbf{R}^{\mathbf{2}}$ \\
Freundlich & 2.36 & 11.56 & 0.6591 \\
\hline
\end{tabular}




\section{Effect of foreign ions}

The absorbing capacity of the adsorbent in the presence of different ions was measured using 15 $\mathrm{mL}$ of synthetic wastewater containing different heavy metals and with a pH value of 2 . Approximately $0.05 \mathrm{~g}$ of adsorbent material was immersed into $15 \mathrm{~mL}$ of synthetic wastewater for 3 hours. The initial concentration of all metal cations was $50 \mathrm{mg} / \mathrm{L}$. The $\mathrm{Au}(\mathrm{III}), \mathrm{Cu}(\mathrm{II}), \mathrm{Pb}$ (II) and $\mathrm{Cd}(\mathrm{II})$ amounts absorbed by the material were $65,1,5$, and $3 \mathrm{mg} / \mathrm{g}$, respectively. Therefore, the Au(III) ions had a much higher binding capacity than that of the other ions. Higher affinity of $\mathrm{Au}$ (III) ions is attributable to the high amount of $\mathrm{NH}_{2}$ groups in the structure.

\section{CONCLUSIONS}

The most appropriate $\mathrm{pH}$ value was 2 and adsorption time for $\mathrm{Au}$ (III) adsorption was 3 hours. The best fit for the adsorption was the Langmuir adsorption and thus, the adsorption in the study was determined to be a single-layer adsorption. Adsorption capacity was $116.27 \mathrm{mg} / \mathrm{g}$, which is a considerably high value. The study showed that the polyethyleneimine-coated silica nanoparticles (PEISiNP) were effective adsorbents for the separation of $\mathrm{Au}$ (III) ions from aqueous solutions.

\section{REFERENCES}

1. Souza C, Majuste D, Dantas MSS, Ciminelli VST. Selective adsorption of gold over copper cyanocomplexes on activated carbon. Hydrometallurgy. 2014;147-148:188-95.

2. Sheel A, Pant D. Recovery of gold from electronic waste using chemical assisted microbial biosorption (hybrid) technique. Bioresour Technol. 2018;247:1189-92.

3. Chen W, Geng Y, Hong J, Dong H, Cui X, Sun M, Zhang Q. Life cycle assessment of gold production in China. J. Clean Prod. 2018; 179:143-50.

4. Syed S. Recovery of gold from secondary sources-A review. Hydrometallurgy. 2012;115116:30-51.

5. Cayumil R, Khanna R, Rajarao R, Mukherjee PS, Sahajwalla $V$. Concentration of precious metals during their recovery from electronic waste. Waste Manage. 2016;57:121-30.

6. Papaiconomou N, Vite G, Goujon N, Lévêque JM, Billard I. Effient removal of gold complexes from water by precipitation or liquid-liquid extraction using ionic liquids. Green Chem. 2012;14:2050-6.

7. Zhang $\mathrm{H}$, Jeffry $\mathrm{CA}$, Jeffey MI. Ion exchange recovery of gold from iodineiodide solutions. Hydrometallurgy. 2012;125-126:69-75.
8. Xie RF, Hu QF, Yang GY, Chen J, Han YS, Zhao $\mathrm{YH}$, Li Z. Solid-phase extraction gold from alkaline cyanide solution with quaternary ammonium surfactant. Rare Metals. 2016;35:282-8.

9. Urucu $O A$, Gündüz $Z Y$, Deniz $S$, Yetimoglu EK, Aydin A. A novel ligand for cloud point extraction to determine gold content in ore samples. Environ. Chem. Lett. 2014;12:449-53.

10. Kashefi K, Tor JM, Nevin KP, Lovley DR. Reductive precipitation of gold by dissimilatory $\mathrm{Fe}$ (III)-reducing bacteria and archaea. Appl Environ Microbiol. 2001;67:3275-9.

11. Awual MR, Khaleque, MA, Ferdows M, Sarwaruddin-Chowdhury AM, Yaita T. Rapid recognition and recovery of gold(III) with functional ligand immobilized novel mesoporous adsorbent. Microchemical J. 2013;110:591-8.

12. Zhang $Y, X u$, Zhang $S$, Liu J, Zhou J, Xu H, Xiao $\mathrm{H}$, Li J. Preparation of thiolmodifid $\mathrm{Fe}_{3} \mathrm{O}_{4} @ \mathrm{SiO}_{2}$ nanoparticles and their application for gold recovery from dilute solution. Sep Purif Technol. 2013;116:391-7.

13. Villalobos LF, Yapici T, Peinemann KV. Polythiosemicarbazide membrane for gold recovery. Sep. Purif. Technol. 2014;136:94-104.

14. Moradi O, Zare K, Monajjemi M, Yari M, Aghaie $\mathrm{H}$. The studies of equilibrium and thermodynamic adsorption of $\mathrm{Pb}(\mathrm{II}), \mathrm{Cd}(\mathrm{II})$ and $\mathrm{Cu}(\mathrm{II})$ ions from aqueous solution onto SWCNTs and SWCNT $-\mathrm{COOH}$ surfaces, fullerenes. Fuller. Nanotub. Carbon Nanostructures. 2010;18:285-302.

15. Moradi O, Aghaie M, Zare K, Monajjemi M, Aghaie $\mathrm{H}$. The study of adsorption characteristics $\mathrm{Cu}^{2+}$ and $\mathrm{Pb}^{2+}$ ions onto PHEMA and P(MMA-HEMA) surfaces from aqueous single solution. J Hazard Mater. 2009;170:673-9.

16. Farghali AA, Abdel-Tawab HA, Abdel-Moaty SA, Khaled R. Functionalization of acidifid multi-walled carbon nanotubes for removal of heavy metals in aqueous solutions. J Nanostructure Chem. 2017;7:101-11.

17. Zhang G, Zhou $Y$, Ding $Z$, Fu L, Wang S. Nanosilica-supported thiosemicarbazideglutaraldehyde polymer for selective $\mathrm{Au}(\mathrm{III})$ removal from aqueous solution. RSC Advances. 2017;7:55215-23.

18. Li H, Wang $X$, Cao L, Zhang $X$, Yang C. Gold recovery PVDF membrane functionalized with thiosemicarbazide. Chem Eng J. 2015;280:399-408. 
19. Lin G, Wang S, Zhang L, Hu T, Peng J, Cheng $\mathrm{S}$, Fu L. Synthesis and evaluation of thiosemicarbazide functionalized corn bract for selective and effient adsorption of $\mathrm{Au}$ (III) from aqueous solutions. J Mol Liq. 2018;258:235-43.

20. Mahdiani M, Soofivand F, Ansari F, SalavatiNiasari M. Grafting of $\mathrm{CuFe}_{12} \mathrm{O}_{19}$ nanoparticles on CNT and graphene: eco-friendly synthesis, characterization and photocatalytic activity. J Clean Prod. 2018;176:1185-97.

21. Ansari F, Sobhani A, Salavati-Niasari M. Simple sol-gel synthesis and characterization of new $\mathrm{CoTiO}_{3} / \mathrm{CoFe}_{2} \mathrm{O}_{4}$ nanocomposite by using liquid glucose, maltose and starch as fuel, capping and reducing agents. J Colloid Interface Sci. 2018;514:723-32.

22. Naguib HM, Ahmed MA, Abo-Shanab ZL. Silane coupling agent for enhanced epoxy-iron oxide nanocomposite. J Mater Res Technol. 2018;7:21-8.

23. Sun Y, Zhang Z, Wong CP. Study on monodispersed nano-size silica by surface modification for underfill applications. J Colloid Interface Sci. 2005;292:436-44.

24. Moisala A, Li Q, Kinloch IA, Windle AH. Thermal and electrical conductivity of single-and multi-walled carbon nanotube-epoxy composites. Compos Sci Technol. 2006;66: 1285-92.

25. Lee JY, Chen C, Cheng H, Li SHY. Adsorption of $\mathrm{Pb}$ (II) and $\mathrm{Cu}$ (II) metal ions on functionalized largepore mesoporous silica. Int J Environ Sci Technol. 2016;13:65-76.

26. Mansa RF, Sipaut CS, Rahman IA, Yusof NSM, Jafarzadeh M. Preparation of glycine-modified silica nanoparticles for the adsorption of malachite green dye. J Porous Mater. 2016;23:35-46.

27. Wang L, Cheng C, Tapas S, Lei J, Matsuoka M, Zhang J, Zhang F. Carbon dots modified mesoporous organosilica as an adsorbent for the removal of 2,4-dichlorophenol and heavy metal ions. J Mater Chem A. 2015;3:13357-64.

28. Zhuang $M-Y$, Jiang $X-P$, Ling $X-M, X u M-Q$, Zhu $Y-H$, Zhang $Y-W$. Immobilization of glycerol dehydrogenase and NADH oxidase for enzymatic synthesis of 1,3-dihydroxyacetone with in situ cofactor regeneration. J Chem Technol Biotechnol. 2018;156:1-10.

29. Dixit CK, Bhakta S, Macharia J, Furtado J, Suib SL, Rusling JF. Novel Epoxy-Silica Nanoparticles to Develop Non-Enzymatic Colorimetric Probe for Analytical Immuno/Bioassays. Anal Chim Acta. 2018; 1028:77-85.
30. Chruściel JJ, Leśniak E. Modification of epoxy resins with functional silanes, polysiloxanes, silsesquioxanes, silica and silicates. Prog Polym Sci. 2015;41:67-121.

31. Fırlak M, Kahraman MV, Yetimoğlu EK, Zeytuncu B. Adsorption of Ag (I) ions from aqueous solutions using photocured thiol-ene hydrogel. Sep Purif Technol. 2013;48:2860-70.

32. He X, Rytöluoto I, Anyszka R, Mahtabani A, Saarimäki E, Lahti K, Paajanen M, Dierkes W, Blume A. Surface Modification of Fumed Silica by Plasma Polymerization of Acetylene for PP/POE Blends Dielectric Nanocomposites. Polymers. 2019;11:1957-78.

33. Gruian C, Vanea E, Simon S, Simon V. FTIR and XPS studies of protein adsorption onto functionalized bioactive glass. BBA-Proteins Proteom. 2012;1824:873-81.

34. Michel $\mathrm{R}$, Pasche $\mathrm{S}$, Textor M, Castner DG. Influence of PEG architecture on protein adsorption and conformation. Langmuir. 2005;21:12327-32.

35. Zhao Y, Zou J, Shi W, Tang L. Preparation and characterization of mesoporous silica spheres with bimodal pore structure from silica/hyperbranched polyester nanocomposites. Micropor Mesopor Mat. 2006; $92: 251-8$.

36. Nhavene EPF, Silva WM, Junior RRT, Gastelois PL, Venâncio T, Nascimento R, Batista RJC, Machado CR, Macedo WAA, Sousa EMB. Chitosan grafted into mesoporous silica nanoparticles as benznidazol carrier for Chagas diseases treatment. Micropor Mesopor Mat. 2018;272:265-75.

37. Yu JG, Le $Y$, Cheng $B$. Fabrication and $\mathrm{CO}_{2}$ adsorption performance of bimodal porous silica hollow spheres with aminemodifed surfaces. RSC Advances. 2012;2:6784-91.

38. Feifel SC, Lisdat F. Silica nanoparticles for the layer-by-layer assembly of fully electro-active cytochrome c multilayers. J. Nanobiotechnology. 2011;9:59-71.

39. Ammar S, Ramesh K, Vengadaesvaran B, Ramesh S, Arof AK. Amelioration of anticorrosion and hydrophobic properties of epoxy/PDMS composite coatings containing nano $\mathrm{ZnO}$ particles. Prog Org Coat. 2016;92:54-65.

40. Li C, Wan J, Kalali EN, Fan H, Wang D-Y. Synthesis and characterization of functional eugenol derivative based layered double hydroxide and its use as a nanoflame-retardant in epoxy resin. J Mater Chem A. 2015;3:3471-9. 
41. Chen $F$, Lu $Y$, Liu $X$, Song J, He G, Tiwari MK, Carmalt CJ, Parkin, IP. Table Salt as a Template to Prepare Reusable Porous PVDF-MWCNT Foam for Separation of Immiscible Oils/Organic Solvents and Corrosive Aqueous Solutions. Adv Funct Mater. 2017;27:1702926-37.

42. Lu L, Pan J, Li G. Recyclable high-performance epoxy based on transesterification reaction. J Mater Chem A. 2017;5:21505-13.

43. Omurlu C, Baran JR, Nguyen QP. Adsorption of Surface Functionalized Silica Nanoparticles onto Mineral Surfaces and Decane/Water Interface. J Nanopart Res. 2012;14:1246-56.

44. Baghban N, Yilmaz E, Soylak M. Nanodiamond/ $\mathrm{MoS}_{2}$ nanorod composite as a novel sorbent for fast and effective vortex-assisted micro solid phase extraction of lead(II) and copper(II) for their flame atomic absorption spectrometric detection. J Mol Liq. 2017;234: 260-7.

45. Ngatijo-Basuki R, Rusdiarso B, Nuryon N. Sorption-desorption profile of $A u(I I I)$ onto silica modified quaternary amines (SMQA) in gold mining effluent. J Environ Chem Eng. 2020;8:103747- 87.

46. Aydın-Urucu O, Aracıer DE, Çakmakçi E. Allylimidazole containing OSTE based photocured materials for selective and efficient removal of gold from aqueous media. Microchem J. 2019;146:9971003.

47. Mihăilescu $M$, Negrea $A$, Ciopec $M$, Davidescu CM, Negrea P, Narcis D, Rusu G. Gold (III) adsorption from dilute waste solutions onto Amberlite XAD7 resin modified with L-glutamic acid. Sci. Rep. 2019;9:8757-69.

48. Kılıc AG, Malcı S, Çelikbıçak Ö, Sahiner N, Salih B. Gold recovery onto poly(acrylamide-allylthiourea) hydrogels synthesized by treating with gamma radiation. Anal. Chim. Acta. 2005;547:18-25.

49. Beyler-Çiğil A, Aydın-Urucu O, Kahraman MV. Nanodiamond-containing polyethyleneimine hybrid materials for lead adsorption from aqueous media. J Appl Polym. 2019;136:48241-50. 